\title{
EXPERIMENTAL STUDY ON THE TORSIONAL BEHAVIOUR OF RECYCLED AGGREGATE CONCRETE BEAMS
}

\author{
D.V.Lokesh ${ }^{1}$, I. Jaagruthi' ${ }^{2}$, Ch.Naga Satish Kumar ${ }^{3}$ \\ ${ }^{1}$ Student, Department of Civil Engineering ,Bapatla Engineering College, Bapatla-522101 \\ ${ }^{2}$ Student, Department of Civil Engineering ,Bapatla Engineering College, Bapatla-522101 \\ ${ }^{3}$ Professor, Department of Civil Engineering ,Bapatla Engineering College, Bapatla-522101
}

\begin{abstract}
In the present paper an experimental investigation was carried out to study the torsional behavior of recycled aggregate beams of size $150 \mathrm{~mm} \times 150 \mathrm{~mm} \times 800 \mathrm{~mm}$ using M 30 mix. This experimental study consists of testing three beams of natural aggregate and twelve beams made by using different proportions of recycled aggregate i.e., 25\%, 50\%, 75\% and 100\% replacements of the natural aggregate with the recycled aggregate. After testing the beams for torsion, the angle of twist vs torque graphs were drawn. From the experimental results it was observed that the torsional decreases with increase in the percentage of recycled aggregates and also found that up to $50 \%$ replacement of aggregates the strength reduction is less and not even $10 \%$ in case of torsional strength. Therefore the usage of recycled aggregates up to $50 \%$ can be acceptable.
\end{abstract}

Key words: Concrete, Recycled aggregates, Natural aggregate ,Torsion.

\section{INTRODUCTION}

The issues of sustainability are of prime concerns these days as we use large amount of natural resources for producing materials such as concrete. The recent trend in construction industry is to use the alternative source of construction materials which can substitute the use of basic materials in order to reduce environmental impact in terms of energy consumption, pollution, waste disposal and global warming. The use of Recycled aggregate in concrete has generated interest in civil engineering construction regarding sustainable development as it is the means of achieving more environment friendly concrete.

Torsion leads to another type of brittle failure of Concrete structures. Torsion is a major factor to consider in the design of many kinds of reinforced concrete structures, including space frames, beams that support cantilever slabs or balconies, horizontally curved beams, spandrel beams, spiral staircases, skew bridges and so on. Generally pure torsion is rarely present in structural members. However, torsion forms one of the basic structural actions besides flexure, shear and axial compression/tension. In order to transfer torsion moments such as these, reinforced concrete units need to have corresponding torsion carrying capacities. Torsional failure is an undesirable brittle failure that should be avoided specially in the earthquake prone areas.

Many researchers had attempted to study the effect of recycled aggregate on strength and durability properties of concrete [Sami W. Tabsh et al ${ }^{1}$, Jian Yang et.al ${ }^{2}$, Valeria Corinaldesi $^{3}$ Gholamreza Fathifazl et al ${ }^{4}$,Ashraf $M$. Wagih et al ${ }^{\mathbf{5}}$, Katrina McNeil, and Thomas H.-K. Kang ${ }^{6}$, O. Cakir ${ }^{7}$, , D. Soares et al ${ }^{8}$ ] and also some researchers had studied the torsional strength of concrete[,Ch. N. Satish Kumar and T.D. Gunneswara Rao ${ }^{9}$ ]. Many studies have been reported on recycled aggregate and torsional strength of concrete separately in general. However the studies on torsional strength of recycled aggregate are limited.

In the present paper, our main attention is to study the effect of recycled aggregate on torsional behavior of concrete. The parameter considered for this study is percentage of replacement of natural aggregate with recycled aggregate $(25 \%, 50 \%, 75 \%$ and $100 \%)$.

\section{EXPERIMENTAL PROGRAM:}

The experimental program was designed to study the torsional behavior concrete beams of size $150 \mathrm{~mm} \times 150 \mathrm{~mm}$ $\mathrm{x} 800 \mathrm{~mm}$. The main variable in this experimental program is percentage of replacement of natural aggregate with recycled aggregate i.e. $0 \%, 25 \%, 50 \%, 75 \%$ and $100 \%$. All beams were loaded by opposite couples at their ends and loads were applied through bearing plates. Fig 1 shows the schematic arrangement of the beam specimen subjected to torsion.

\section{MATERIAL DETAILS}

Ordinary Portland cement (OPC) of 53 grade conforming to IS 8112:1989 with specific gravity of 3.15 was used in Concrete mix [10]. Fine aggregate conforming to Zone II of IS 383:1970 was used[11].Crushed coarse aggregate passing through $20 \mathrm{~mm}$ sieve with specific gravity 2.7 was used The recycled aggregate used in this investigation was collected from a single source, from a demolished 35 year old building. The specific gravity of recycled aggregate is 2.81 . The details of mix proportions are listed in Table 1. 


\section{CASTING:}

Cubes of $100 \mathrm{~mm}$ size were used to determine the compressive strength of concrete. Cylinders with $150 \mathrm{~mm}$ diameter and $300 \mathrm{~mm}$ length were used to determine the splitting tensile strength of concrete. Specially prepared moulds were used for casting the beam specimens of size $150 \mathrm{~mm} \times 150 \mathrm{~mm} \times 800 \mathrm{~mm}$. A needle vibrator was used for compaction. After casting the specimens, demoulding was carried out with a time gap of 24 hours. All the specimens were water cured for 28 days. After removing the specimens from the curing tank they are allowed to dry for some period. They were cleaned with cotton waste to remove the dust particles. All the specimens were white washed with white cement. In this experimental investigation a total of fifteen concrete beams were casted.

\section{TEST SETUP AND TESTING PROCEDURE:}

All the specimens were tested on the Universal testing Machine of $1000 \mathrm{kN}$ capacity. The beam specimens were loaded by opposite couples at their ends and loads were applied through bearing plates. The bearing plates, made of stainless steel, were square, of sizes $25 \mathrm{~mm}$ and thickness of plates was $10 \mathrm{~mm}$. At both ends of the central test region, twist meters were used to measure the twist of the beam. The twist meter consists of a steel frame and the steel arms were welded to the vertical frame. The frame can be attached to the beam by means transverse screws. The dial gauges are placed in such that the tips of dial gauges touch the arms of the frame. The distance between the dial gauges was noted for calculation of twist. Two twist meters were provided, one at the either end of the test region to measure the twist per unit length of the beam. A photograph of the test setup is shown in Fig 2.

The beam specimens were loaded through a steel transfer beam by the Universal testing machine under load rate control to generate pure torsion. At the regular stage of loading, the readings of dial gauge attached to twist meters were recorded. The load at which failure occurred is recorded. To find out the mechanical properties of concrete, three companion cubes, three companion cylinders were tested on the ACTM $3000 \mathrm{kN}$ testing machine. The average values of the mechanical properties of concrete are listed in table 2 .

\section{TEST RESULTS AND DISCUSSIONS:}

All the beam specimens were tested under pure torsion, measuring the twist for each and every increment of torque. The ultimate torque and twist at failure were presented in table 3.To understand the torsional behavior of concrete beams the torque and twist graphs were drawn. (fig.3). All beams were failed suddenly into two pieces. The fracture surfaces had an inclination of 450 and were slightly warped on one side, terminating with a smaller inclination at the opposite side. A photograph of the failure surface of the beams is shown in Fig 5 and also the crack pattern of beams in terms of the distances from one edge of the beam was presented in the Table4 (fig 4). The failure angle of all the beams is in between $400-50 \mathrm{o}$. From the table 3, it was observed that the torsional strength decreases with increase the percentage of replacement of natural aggregate with recycled aggregate. For $50 \%$ replacement, the strength reduction is up to $8.51 \%$ and for $100 \%$ replacement, the strength reduction is up to $17.02 \%$. Fig 5 shows the variation of torsional strength with percentage of replacement of recycled aggregate. Fig 6 and Fig 7 shows the variation of compressive and split tensile strength with percentage of replacement of recycled aggregate. From Fig 6 and Fig 7, it was observed that on replacing $25 \%$ of aggregates, the compressive strength is reduced by $13.09 \%$ and split tensile strength is reduced by $6.33 \%$, on replacing $50 \%$ of aggregates, the strength is reduced by $14.58 \%$ and split tensile strength is reduced by $17.9 \%$, on replacing $75 \%$ of aggregates, the strength is reduced by $27.36 \%$ and split tensile strength is reduced by $28.37 \%$, on replacing $100 \%$ of aggregates, the strength is reduced by $28.68 \%$ and split tensile strength is reduced by $33.88 \%$. The photographs of the tested beams are shown in Fig 8.

\section{CONCLUSIONS:}

Based on the tests on fifteen beam specimens, the following conclusions have been drawn:

Torsional strength decreases with increase the percentage of replacement of natural aggregate with recycled aggregate .

It was found that up to $50 \%$ replacement of aggregates the Torsional strength reduction is less and not even $10 \%$. Therefore the usage of recycled aggregates up to $50 \%$ can be acceptable.

Twist at failure decreases with increase the percentage of replacement of natural aggregate with recycled aggregate.

1. The Split tensile strength of concrete also decreased with increase in the $\%$ replacement of recycled aggregates. On replacing $50 \%$ of aggregates, the strength is reduced by $17.9 \%$. On replacing $100 \%$ of aggregates, the strength is reduced by $33.88 \%$.

2. The Compressive strength of concrete reduced with increase in the \% replacement of recycled aggregates. On replacing 50\% of aggregates, the strength is reduced by $14.58 \%$.On replacing $100 \%$ of aggregates, the strength is reduced by $28.68 \%$.

\section{ACKNOWLEDGEMENTS}

The authors are highly thankful to the authorities of Bapatla Engineering College, Bapatla, for providing facilities for carrying out this work.

\section{REFERENCES}

[1] Sami W. Tabsh, Akmal S. Abdelfatah, "Influence of recycled concrete aggregates on strength properties of concrete", Construction and Building Materials 23 (2009) 1163- 1167

[2] Jian Yang, Qiang Du , Yiwang Bao "Concrete with recycled concrete aggregate and crushed clay bricks", Construction and Building Materials 25 (2011) 19351945. 
[3] Valeria Corinaldesi, "Mechanical and elastic behaviour of concretes made of recycledconcrete coarse aggregates", Construction and Building Materials 24 (2010) 1616-1620.

[4] Gholamreza Fathifazl et al, "Creep and drying shrinkage characteristics of concrete produced with coarse recycled concrete aggregate" ,Cement \& Concrete Composites 33 (2011) 1026-1037.

[5] Ashraf M. Wagih et al, "Recycled construction and demolition concrete waste as aggregate for structural concrete", HBRC Journal (2013) 9, 193-200.

[6] Katrina McNeil, and Thomas H.-K. Kang, "Recycled Concrete Aggregates: A Review", International Journal of Concrete Structures and Materials Vol.7, No.1, pp.61-69, March 2013.

[7] O. Cakır, "Experimental analysis of properties of recycled coarse aggregate (RCA) concrete with mineral additives", Construction and Building Materials 68
(2014) 17-25. 15.Monalisa Behera et al, "Recycled aggregate from $C \& D$ waste $\&$ its use in concrete - A Break through towards sustainability in construction sector: A review", Construction and Building Materials 68 (2014) 501-516.

[8] D. Soares, J. de Brito, J. Ferreira, J. Pacheco, "In situ materials characterization of fullscale recycled aggregates concrete structures", Construction and Building Materials 71 (2014) 237-245.

[9] Ch.N.Satish kumar \& T.D.Gunneswar Rao "Torsional Response of plain concrete members using mode-II fracture energy”, ICJ ,November 2013.

[10] Indian standard for high strength ordinary Portland cement, IS 8112-1989, Bureau of Indian standards, New Delhi.

[11]Indian Standards for coarse and fine aggregate from natural sources for concrete, IS383:1970, second revision, Bureau of Indian standards, New Delhi.

Table 1: Mix proportions

\begin{tabular}{|c|c|c|c|c|}
\hline Mix & Cement & Fine aggregate & Coarse aggregate & Water \\
\hline M40 & 1 & 1.585 & 3.13 & 0.45 \\
\hline
\end{tabular}

Table 2: Mechanical properties

\begin{tabular}{|c|c|c|}
\hline $\begin{array}{c}\text { \% of Recycled } \\
\text { Aggregate }\end{array}$ & $\begin{array}{c}\text { Compressive Strength } \\
\left(\mathbf{N} / \mathbf{m m}^{\mathbf{2}}\right)\end{array}$ & $\begin{array}{c}\text { Split Tensile Strength } \\
\left(\mathbf{N} / \mathbf{m m}^{\mathbf{2}}\right)\end{array}$ \\
\hline $0 \%$ & 50.94 & 3.63 \\
\hline $25 \%$ & 44.27 & 3.40 \\
\hline $50 \%$ & 43.51 & 2.98 \\
\hline $75 \%$ & 37.00 & 2.60 \\
\hline $100 \%$ & 36.33 & 2.40 \\
\hline
\end{tabular}

Table 3: Ultimate Torque and Twist of Tested specimens

\begin{tabular}{|c|c|c|}
\hline $\begin{array}{c}\text { \% of Recycled } \\
\text { Aggregates }\end{array}$ & $\begin{array}{c}\text { Twist at failure } \\
(\mathrm{Rad} / \mathrm{m})\end{array}$ & $\begin{array}{c}\text { Torsional Moment } \\
(\mathrm{Kn}-\mathrm{m})\end{array}$ \\
\hline 0 & 0.0168 & 4.7 \\
\hline 25 & 0.0162 & 4.4 \\
\hline 50 & 0.0125 & 4.3 \\
\hline 75 & 0.0112 & 4.1 \\
\hline 100 & 0.0104 & 3.9 \\
\hline
\end{tabular}

Table 4: Details of failure surface of tested beams specimens.

\begin{tabular}{|c|c|c|c|c|}
\hline $\begin{array}{c}\text { \% of Recycled } \\
\text { Aggregates }\end{array}$ & $\mathrm{X}_{1} \mathrm{~mm}$ & $\mathrm{X}_{2} \mathrm{~mm}$ & $\mathrm{X}_{3} \mathrm{~mm}$ & $\mathrm{X}_{4} \mathrm{~mm}$ \\
\hline $0 \%$ & 44 & 33 & 24 & 15 \\
\hline $25 \%$ & 43 & 35 & 22 & 25 \\
\hline $50 \%$ & 52 & 37 & 29 & 16 \\
\hline $75 \%$ & 48 & 36 & 27 & 19 \\
\hline
\end{tabular}




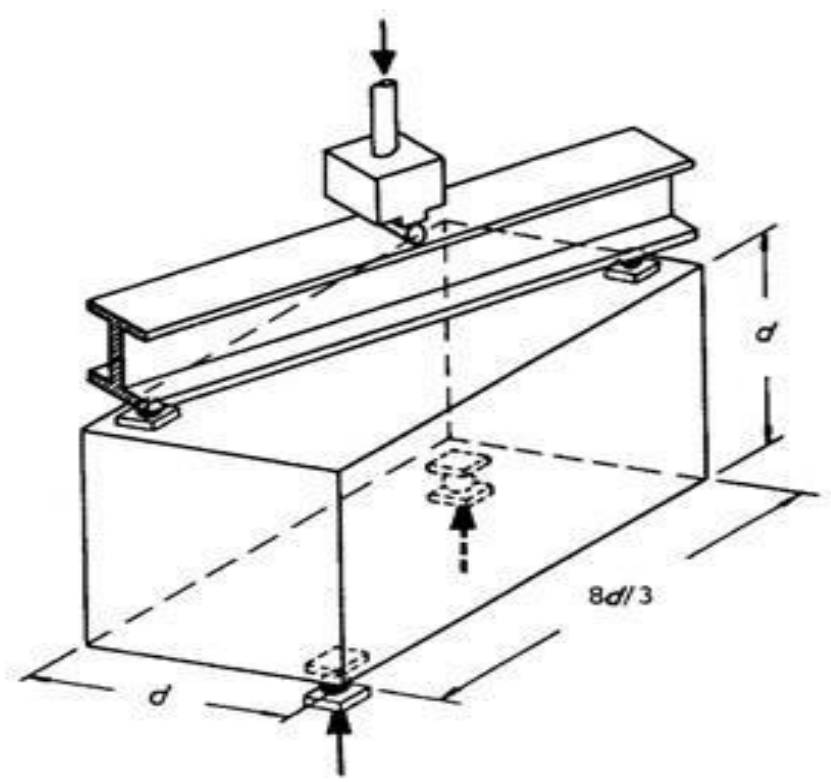

Fig 1: schematic arrangement of the beam specimen subjected to torsion.

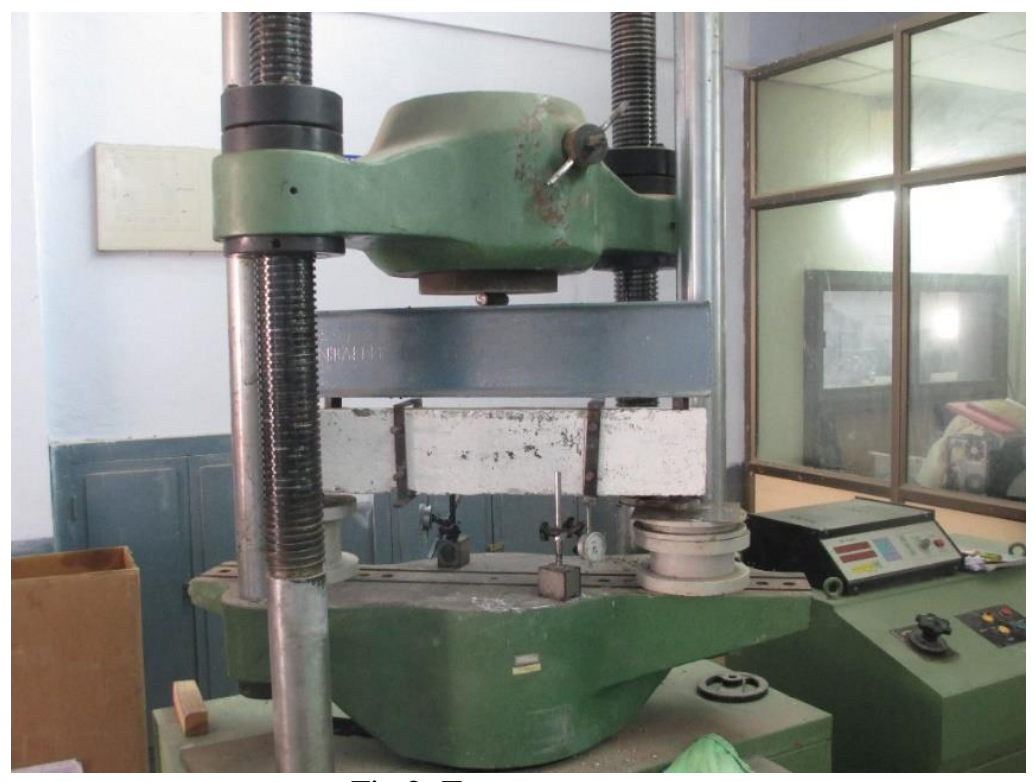

Fig 2: Test setup. 


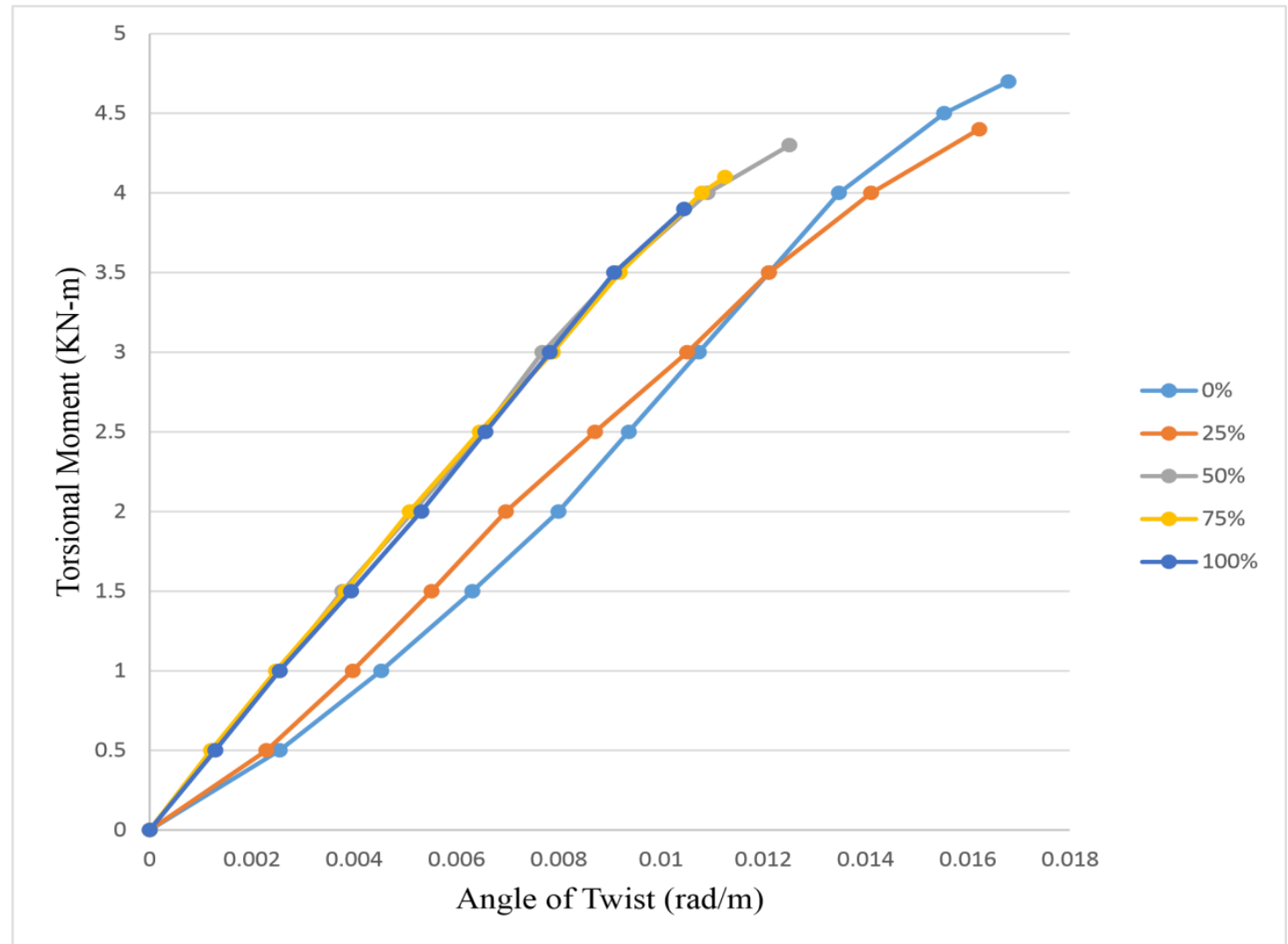

Fig 3: Torque-twist curves

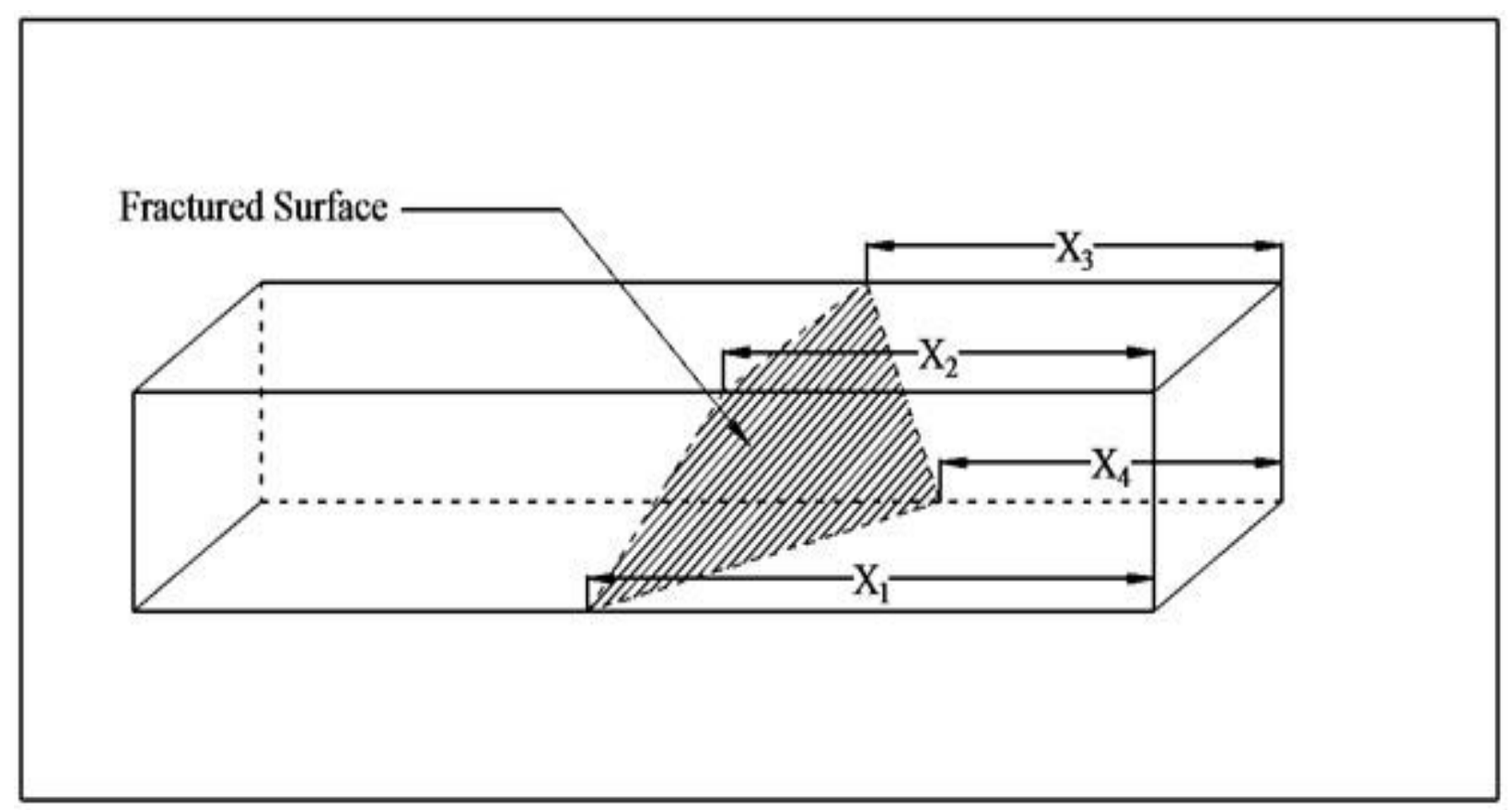

Fig 4: Crack pattern of the beams 


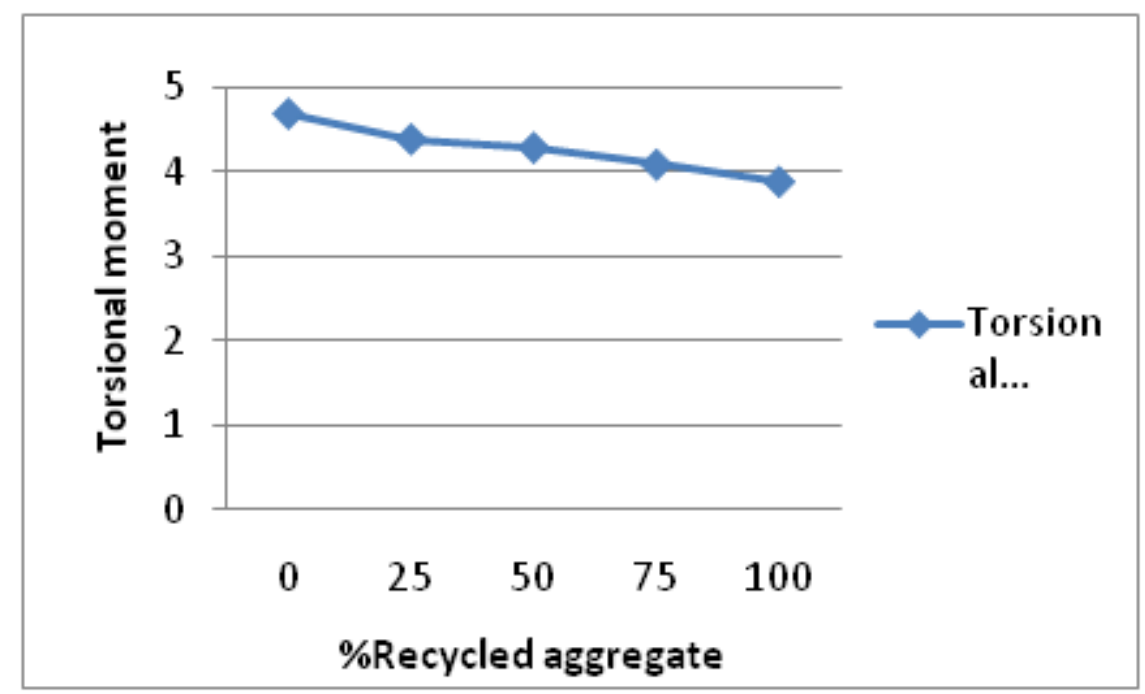

Fig 5: Variation of torsional strength with percentage replacement of recycled aggregate

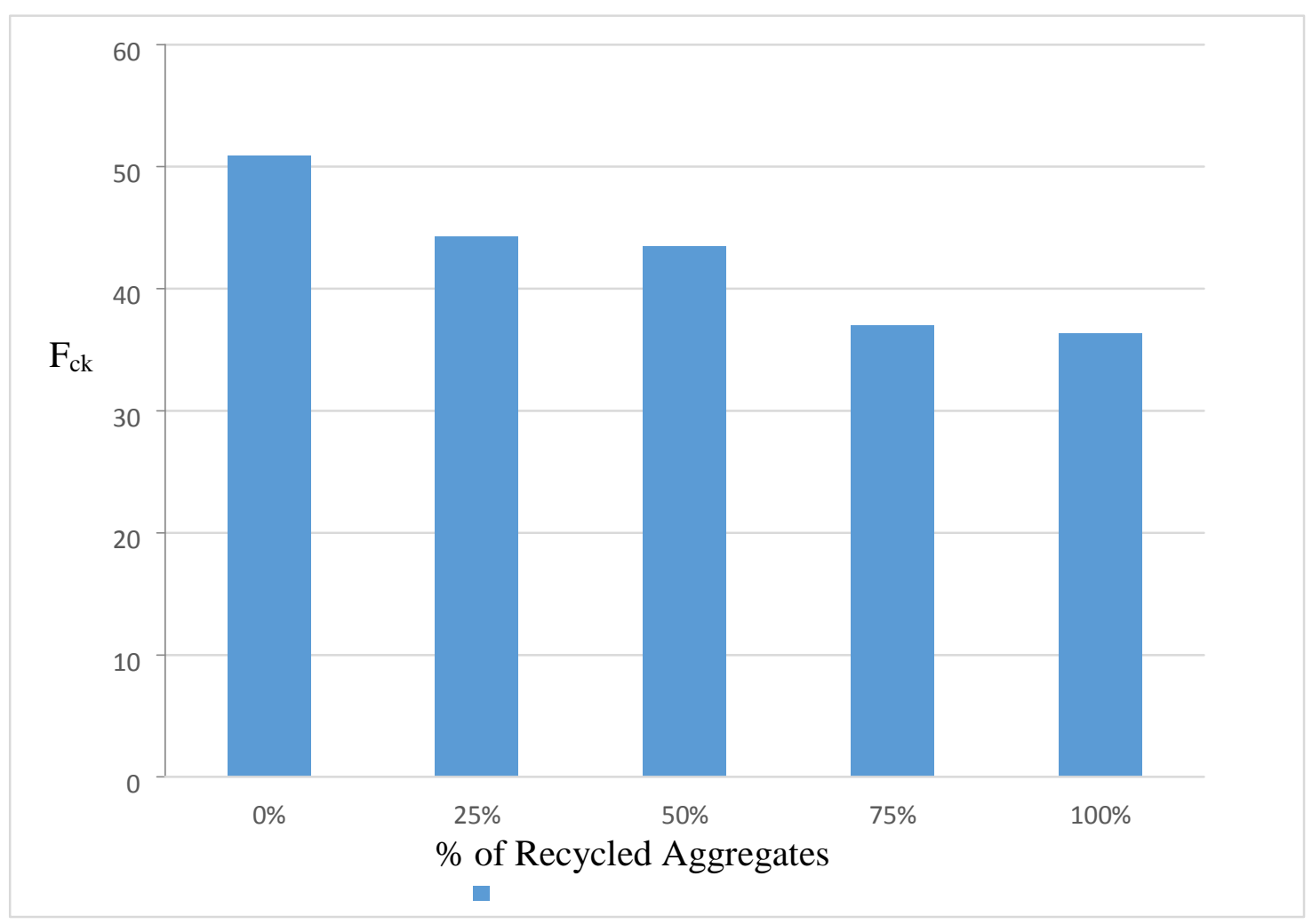

Fig 6: Variation of compressive strength with percentage replacement of recycled aggregate 


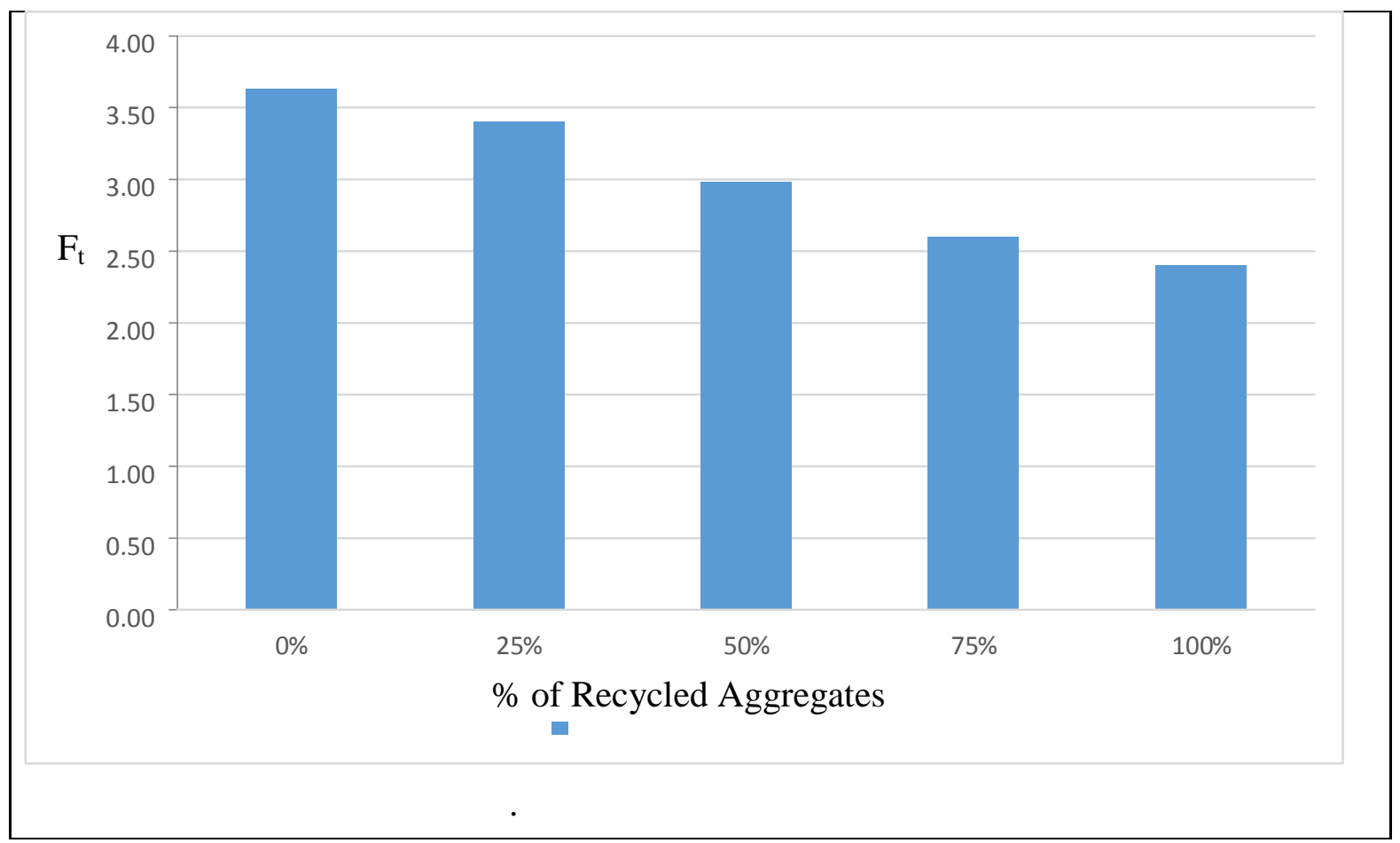

Fig 7: Variation of split tensile strength with percentage replacement of recycled aggregate
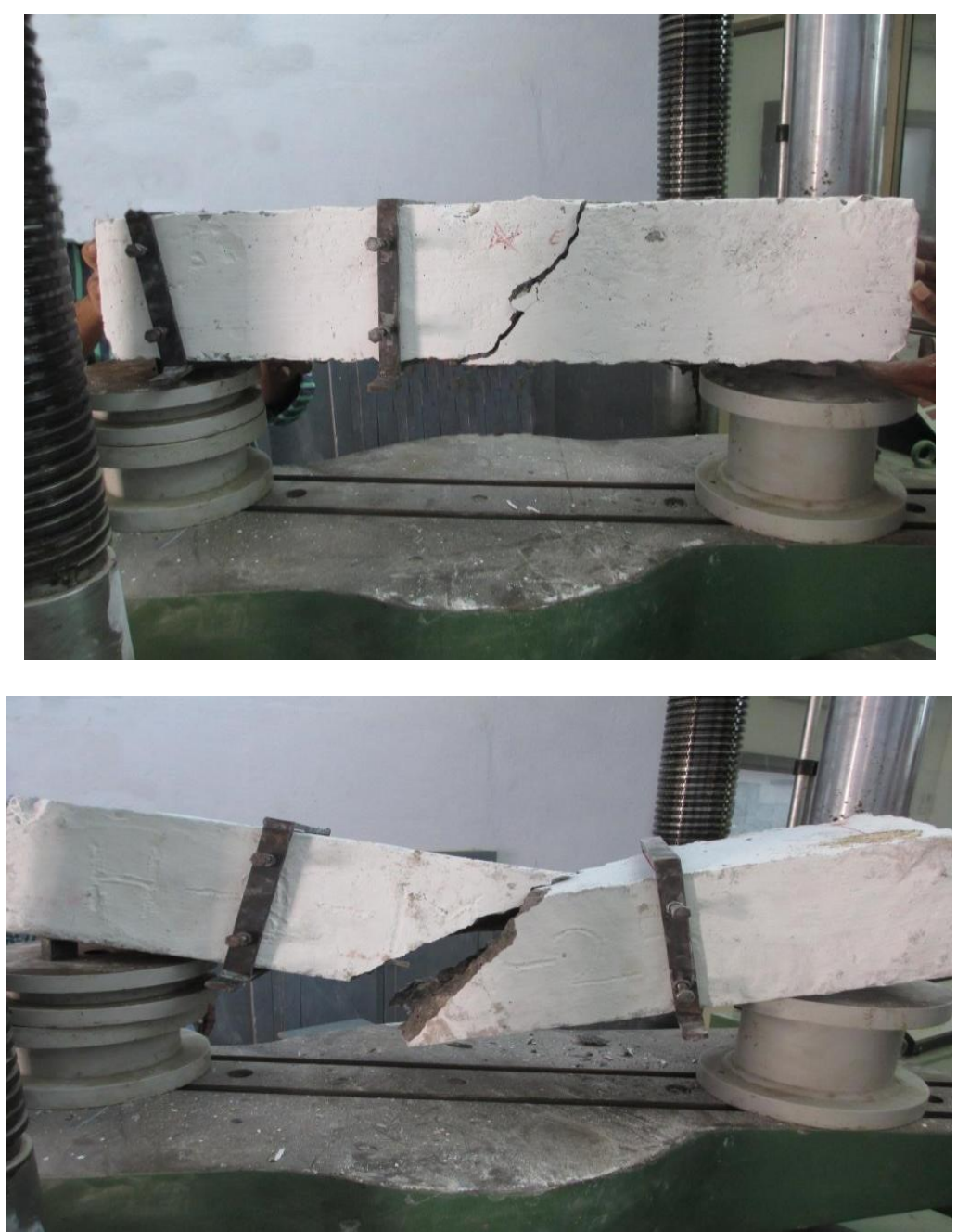

Fig 8: Photograph of specimens after the test. 